\title{
WOMEN'S VIEWS ON ANXIETY IN PREGNANCY AND THE USE OF ANXIETY INSTRUMENTS: A Qualitative study
}

Kerry Evans, RM, BSc, MA

Nottingham University Hospitals NHS Trust UK

Labour Suite, City Campus,

Hucknall Road, Nottingham, UK.

NG5 1PB.

Kerry.evans@nuh.nhs.uk

Dr C Jane Morrell, PhD, MPhil, BSc, HV, SRN.

Associate Professor in Health Research, School of Health Sciences, University of Nottingham.

Queen's Medical Centre

Nottingham, UK.

NG7 2UH

Jane.Morrell@nottingham.ac.uk

Professor Helen Spiby, MPhil, SRN, SCM

Professor of Midwifery, School of Health Sciences, University of Nottingham.

$12^{\text {th }}$ Floor Tower Building

Nottingham, UK.

NG7 2RD

Honorary Professor, School of Nursing \& Midwifery, University of Queensland, Brisbane, Australia.

Helen.Spiby@nottingham.ac.uk

No conflict of interest has been declared by the authors.

Funding - The study was funded by an Entry Level Research Scholarship by Wellbeing of Women (London) in association with the Royal College of Midwives and the British Maternal Fetal Medicine Society. 


\section{Abstract}

Objective: To explore women's experience of anxiety in pregnancy and views on the use of anxiety instruments in antenatal care.

Background: Anxiety in pregnancy is associated with adverse birth outcomes, developmental and behavioural problems in infants and postnatal depression. Despite recommendations for routine psychological assessment in pregnancy the optimal methods to identify anxiety in pregnancy have not been confirmed.

Methods: A qualitative study using two focus group discussions was undertaken. Focus group one included women in a community setting and focus group two included women in a hospital clinic setting who had received additional support for anxiety in pregnancy. Participants were women who had given birth within the past nine months and considered themselves to have been anxious during their pregnancy.

Results: Three main themes were identified using template analysis: sources of support, administration of anxiety instruments and the use of instruments to prompt discussion. Women stated anxiety instruments could help them to identify their anxious feelings and prompt a discussion around those feelings. However they expressed concerns surrounding the administration of anxiety instruments and questioned how useful they would be in helping women access help and support.

Conclusions: The introduction of anxiety instruments in antenatal care may present an opportunity to discuss women's emotional health and anxieties. Providing women with sufficient time to discuss their anxious feelings, identified by such instruments, could facilitate access to additional support.

Keywords: Anxiety; Identification; Antenatal; Pregnancy; Focus group discussion; Qualitative

\section{Introduction}

Pregnant and non-pregnant women have similar symptoms of anxiety (National Institute for Health and Care Excellence (NICE), 2014), however in pregnancy, concerns over the wellbeing of the baby, the birth or parenting may present as predominant features (Staneva et al., 2015, Vythilingum, 2009). Symptoms may include feeling overwhelmed, angry and scared, ruminating thoughts, irritability and being unable to relax (Highet et al., 2014; Staneva et al., 2015).

Anxiety in pregnancy can be exacerbated by previous experience of pregnancy and birth problems, including painful labour (Staneva et al., 2015). Women have reported feeling a loss of control over their bodies, confused by ambiguous information and lacking knowledge and understanding of pregnancy and labour (Highet et al., 2014; Keeton et al., 2008; Staneva et al., 2015). Women may delay disclosure of the pregnancy due to fear of miscarriage, especially following assisted conception or previous pregnancy loss (Armstrong \& Hutti, 1998; Armstrong, 2004; Côté-Arsenault \& Donato, 2011; Rowe \& Fisher, 2015; Staneva et al., 2015). Women may feel isolated if they think they are not having a 'perfect pregnancy', resulting in an increased sense of inadequacy, vulnerability and questioning of their ability to be a 'good mother' (Highet et al., 2014; Rowe \& Fisher, 2015; Staneva et al., 2015).

Anxiety in pregnancy is associated with low birthweight for gestational age, prematurity, pregnancy induced hypertension and in children increased anxiety, negative temperament, behavioural and developmental problems (Blair et al., 2011; Cardwell, 2013; Davis \& Sandman, 2012; Ding et al., 2014; Glover, 2014; Littleton et al., 2007; Stein et al., 2014). However the current evidence 
surrounding the effects of anxiety in pregnancy is inconsistent (Stein et al. 2014). The effects of anxiety are often studied alongside depression because of the strong co-morbidity (Glover, 2014). Postnatal depression is often preceded by antenatal depression and anxiety (Coelho et al., 2011; Dunkel Schetter \& Tanner, 2012; Heron et al., 2004; Larsson et al., 2004). Some of the effects on the child formerly attributed to postnatal depression may originate in antenatal anxiety (Evans et al., 2001).

Fetal overexposure to maternal cortisol, downregulation of placental barrier enzymes, increased fetal serotonin exposure and epigenetic changes due to increased maternal anxiety may be factors in fetal programming leading to adverse fetal and infant outcomes (Bonnin et al., 2011; Glover, 2014; Herbert et al., 2006; Mairesse et al., 2007; Mueller \& Bale, 2008; Radtke et al., 2011). However, the underlying causal mechanisms are not yet established (Glover, 2014).

\section{Identification of Anxiety in Pregnancy}

The prevalence of self-reported anxiety symptoms in pregnancy of $14-15 \%$ has been reported (Heron et al., 2004; Rubertsson et al., 2014). The association between maternal anxiety and adverse health outcomes is not inevitable and in order to provide early prevention and treatment strategies it is important to identify women who are at an increased risk of adverse outcomes (Stein et al., 2014). 'Saving Lives, Improving Mothers' Care' (Knight et al. 2015) states that screening for the risk of, or presence of mental disorders is the responsibility of all health professionals in contact with pregnant women. For at least $11 \%$ of pregnant and postnatal women who died by suicide there was either no enquiry or inadequate enquiry about mental health at the antenatal booking appointment. Psychological assessments are recommended as part of routine antenatal care to provide opportunities to offer support and identify women who require urgent psychiatric assessment (Austin et al., 2005, 2008; Austin, 2003; Buist et al., 2006; Knight et al., 2015; NICE, 2014). Psychological instruments used alongside a general discussion about a woman's mental wellbeing may help midwives recognise mental health problems in pregnancy (NICE 2014, O'Hara, 2009; Oates, 2003). However, there is insufficient evidence to support the use of any single method of identification (Austin et al., 2008). Many of the instruments used during pregnancy are adapted from general health questionnaires and require validation in perinatal populations (Alderdice et al., 2012; Meades \& Ayers, 2011). Four recent literature reviews (Alderdice et al., 2012; Evans et al., 2015; Meades \& Ayers, 2011; Morrell et al., 2013) have highlighted the limited research investigating psychometric properties of pregnancy-specific anxiety measures.

Women may not fully acknowledge their level of anxiety and use 'emotional cushioning' and other self-protective mechanisms to cope during stressful pregnancies, suggesting that women's anxiety in pregnancy might be underreported and underestimated (Côté-Arsenault \& Donato, 2011).

There is a paucity of research exploring women's views on anxiety instruments in pregnancy. It is important to develop methods to identify the symptoms of anxiety which pregnant women find relevant and acceptable. The aim of the study was to explore women's experience of anxiety in pregnancy and their views on the use of anxiety instruments in antenatal care.

\section{Methods}

A qualitative methodology using focus group discussions (FGDs) was employed. FGDs rather than individual interviews were selected to encourage interaction and discussion of the topic (Freeman, 
2006). The sharing of experiences enables participants to realise commonalities and generate consensus on the most important issues (Morgan \& Kreuger, 1993). However it should be acknowledged that when discussing sensitive topics within a specific context and culture, individuals may not express their own definitive view (Gibbs, 1997).

\section{Ethical permissions and research governance}

Permission to conduct the research was given in April 2013 by the East Midlands NHS Research Ethics Committee and the Research and Innovation Department of the local NHS Trust who also sponsored the study.

\section{Recruitment and selection}

Local healthcare professionals (HCPs) were contacted and provided with details of the study. The HCPs were asked to introduce the researcher to eligible women and obtain permission for the researcher to make contact to provide further information. Once permission was received, women were sent written information outlining the study and had an opportunity to consider their involvement and ask any questions. Written consent was obtained prior to group commencement.

\section{Participants}

To be included in the study women had to be at least 18 years of age and have given birth within the previous nine months to a healthy full-term infant. The researcher asked women if they considered themselves to have felt anxious during their pregnancy. Women who provided a positive answer and met the inclusion criteria were invited to participate. Women were included regardless of obstetric or medical conditions during pregnancy. Women were excluded from the study if they had received treatment for a severe and enduring mental health condition; did not speak, understand, read and write in the English language or were pregnant.

\section{Data collection and analysis}

During the FGDs women were shown three anxiety instruments used in pregnancy: the Edinburgh Postnatal Depression Scale (EPDS, Cox et al., 1987), the Hospital Anxiety and Depression Scale (HADS, Zigmond \& Snaith, 1983) and the Pregnancy Related Anxiety Questionnaire (PRAQ, Van den Bergh, 1990) and were asked to comment on the relevance and acceptability of all three.

The topic guide for the FGDs facilitated the discussion (Figure 1). The FGDs were audio-recorded and transcribed verbatim. Transcribed data were checked against fieldnotes for accuracy and to remind the researcher of the context of and interactions within discussions. All data were anonymised. Template analysis (King, 2004) was employed to enable an investigation of the data to identify new concepts but also to interrogate the data for themes identified in the literature. An initial template was developed which combined the pre-specified headings from the topic guide and themes resulting from the analysis of the focus group one transcript (King 2004). Focus group two data were coded with respect to the initial template, which was then modified to include the themes from focus group two and then the themes were reapplied to the focus group one transcript. The template was further refined to ensure the template adequately fitted the data.

\section{Findings}

Two groups of women participated in the study. Detailed demographic data were not collected but there were primiparous and multiparous women of different ages and ethnicities in both FGDs. 
Focus group one included fifteen women who were part of an established community postnatal group and who had not received any additional treatment for anxiety during pregnancy. Focus group two included four women who had been referred by their community midwife or obstetrician to a specialist midwife for support with anxiety in pregnancy. The midwife had spent time talking with the women, provided support and advice and helped them to plan their care.

Both FGDs lasted for one and a half hours. A facilitator (KE) ran both groups, supported by cofacilitator (JM) who took contemporaneous fieldnotes. Ground rules were agreed prior to group commencement which included asking participants to respect each other's confidentiality. Common and group specific themes and sub themes identified within the final template are compared for the two groups (Table 1).

Quotations from 15 participants in focus group one were coded as [G1/P1-P15]. Quotations from four participants in focus group two were coded as [G2/P1-P4]. The themes and subthemes are presented below with women's quotations in figures 2-5.

Women from both groups discussed anxieties surrounding miscarriage and fetal loss, loss of control and complications during labour. Women revealed anxieties related to maintaining their pregnancies and the responsibility they felt to keep their unborn babies alive. These concerns were strongly expressed by women who had experienced previous pregnancy loss, who found it difficult to prepare for the baby whilst protecting themselves against further emotional distress. Fears surrounding the pain of labour, loss of control and not knowing what to expect were strongly expressed by primiparous women in both groups. Women who had previously experienced complications during labour and birth were afraid of going through a similar situation.

\section{Theme one: Sources of support}

\section{Women were not able to share their feelings of anxiety with others and felt isolated}

Barriers to disclosing their feelings included not wanting to burden or cause concern to family members. Although supportive, husbands and partners found it difficult to sympathise with their situations. When asked who they talked to about feeling anxious, no participants in focus group one mentioned their midwife. Some participants identified a lack of continuity of carer and midwives' busy schedules as reasons they had not been able to develop a good relationship with their community midwife. Women in focus group two had tried to disclose their anxieties but felt that their midwife did not understand or tried to minimise their feelings. Difficulty in discussing feelings resulted in women from both groups expressing a sense of isolation. Focus group two participants described how they had often struggled with identifying why they were anxious. They knew other women who had been through worse situations and this left them feeling foolish and embarrassed about their own feelings. Women from focus group one found the pressure to conform to the image of a happy, healthy pregnancy led them to feel they were abnormal and made them more reluctant to share their true feelings.

\section{Women felt that connecting with others with similar feelings would help}

Many participants would have liked to talk to others who were going through similar experiences; peer support would have encouraged them to share mutual experiences and therefore feel less 
isolated. Having someone who could empathise with them would have helped them to accept it was normal to feel the way they did, and that other people understood those feelings.

\section{Women received additional support at a time of crisis}

Women in focus group two who had access to support for anxiety in pregnancy, described how they found it impossible to hide their feelings. Some had tried to discuss their feelings with GPs and midwives but found them dismissive or unable to signpost them to additional support. Meeting different midwives at each appointment meant they had to repeatedly explain their situation and feelings which made them feel frustrated. All found the additional support to be helpful, however they were concerned that this had happened at a time of crisis or by chance.

\section{Theme two: Administration of anxiety instruments}

\section{Concerns that instruments would be a tick box exercise}

Both groups highlighted that they would only have been happy to complete an anxiety instrument if they knew the scores would have been used to indicate additional support was needed. None of the participants had been presented with an anxiety instrument in their pregnancy. They considered it could have raised important issues and they were concerned about the administration of an instrument without a supportive discussion. They questioned whether anyone would actually care about their responses, rendering assessment an arbitrary and pointless exercise. Women from focus group one envisaged that anxiety instruments could result in being advised 'not to worry' by way of reassurance, however such advice would again minimise their feelings and lead to greater frustration.

\section{Concerns about providing honest answers}

Concerns about anxiety instruments being a 'tick box' exercise led to discussions in both groups about the willingness to provide honest answers. Some women from focus group one referred to the EPDS (Cox et al. 1987) question 'the thought of harming myself has occurred to me' and could not imagine women wanting to admit that. They expressed concerns about confidentiality and how this information might be used if it was recorded in their medical records, especially whether it could lead to questions about their ability to care for their baby.

\section{Theme three: Instruments prompting discussion Relevance and wording of questions}

When presented with examples of anxiety instruments, participants thought some items could be beneficial in helping women express their feelings, although other items appeared to minimise their feelings or were considered irrelevant in pregnancy. Some EPDS questions (Cox et al. 1987) have a response option of 'for no good reason' (e.g. I have been anxious or worried for no good reason). Participants did not like this wording as they felt they had good reasons for their fears and anxieties.

For some women in focus group one the PRAQ pregnancy specific instrument (Van den Bergh, 1990) was considered helpful to women experiencing severe symptoms but did not reflect their own feelings. They thought women who identified with the PRAQ statements must be 'really struggling' [G1/P5], although they acknowledged that statements such as 'I am afraid the baby will be stillborn or die' could help women feeling these emotions to express their fears honestly. A number of 
participants from focus group one and all focus group two participants could identify with the statements and suggested that it reflected anxieties specific to pregnancy.

\section{Helping to clarify and discuss anxious feelings}

Participants in group two identified with the concepts in the HADS (Zigmond \& Snaith 1983) and liked the way the sentences were presented (e.g. 'Worrying thoughts constantly go through my mind') in that it separated their anxiety into individual topics. They said it was easier to talk about their feelings if they could identify with the statements. Reading the individual statements in the anxiety instruments prompted discussions in both groups about the nature of anxious feelings.

\section{Helping to identify what would help}

The discussion of anxiety instruments led to participants identifying aspects of additional support which may have been welcomed. Women in focus group one found their ongoing postnatal group to be a good source of support and recognised that peer group support would have helped them feel less isolated and would have provided reassurance during pregnancy. They suggested that midwives could facilitate group meetings with women who were experiencing similar feelings.

Women from focus group two also placed importance on meeting others in similar situations, although this would have been preferred alongside individual support. They felt that some pregnant women may have been willing to self refer to additional services if information about access had been available. However, women considered that the amount of support for women experiencing mild or moderate symptoms of anxiety was limited.

\section{Discussion}

Women often lacked the professional support they needed to discuss their anxieties and would have welcomed a greater focus on their emotional health in pregnancy. They attributed inadequacy of emotional support to constraints on midwives' time due to heavy workloads, a lack of awareness of supportive services and problems with continuity of care. Previous studies have reported that midwives have similar concerns which they identified as barriers to providing effective care for pregnant women with mental health problems (Jarrett et al., 2009). To facilitate an effective discussion of women's emotional health, midwives need sufficient time to build a relationship with the woman to enable her to discuss her feelings and access professional support. Women in this study considered that the use of anxiety instruments would have helped to prompt an open discussion with their midwife. Improving midwives' awareness and knowledge through training and an understanding of referral processes and support services, can empower midwives to support women with perinatal mental health problems (Jomeen et al., 2012).

The women were reluctant to share their anxieties with family members, to avoid causing emotional burden. They felt they had to conform to having a positive pregnancy experience. Participants identified additional support that would have been helpful to them. Other studies have described how pregnant women often turn to informal support to meet their emotional needs (Raymond et al., 2014). Women in both groups concluded that peer support would have allowed them to talk openly without burdening or upsetting family members and would have confirmed that they were not unique in their experience. Observing that others have similar feelings has been described as a 
key component of group therapy which reduces stigma around anxiety (Whitfield, 2010; Yalom, 1995).

Both groups discussed the use of anxiety instruments; the most positive comments related to the pregnancy specific questionnaire (PRAQ-R, Van den Bergh, 1990). Participants confirmed that some of the questions surrounding the health of the baby reflected their emotions at the time. During pregnancy the women's difficulty discussing their feelings meant they welcomed the anxiety questionnaires which presented the items in the first person and present tense, ' I feel... , I get... I am afraid...'.

Women's concerns about the use of anxiety instruments in pregnancy related to three areas: the information being used to highlight child protection concerns; completion of anxiety instruments as a tick box exercise without realistic support and referral options; a positive professional relationship would be required to enable the women to provide honest answers. Clinicians should be aware that women's worries and discomfort in disclosing details could affect the utility of anxiety instruments (Côté-Arsenault \& Donato, 2011). Providing a supportive context for the administration of anxiety instruments may help women disclose their true feelings and seek support without concern about being misunderstood (Côté-Arsenault \& Donato, 2011). In the UK, it is a midwife's duty of care to report concerns if they believe someone may be at risk of harm to themselves or others (Nursing and Midwifery Council, 2015). However it should be made clear that the primary aim of instruments is to highlight when women may benefit from further support. It is important that midwives are fully aware of the implications of administering anxiety instruments in pregnancy. This includes providing women with the opportunity to discuss any concerns and signposting to appropriate support. Darwin et al. (2013) identified that psychosocial assessment during pregnancy helped to raise women's own awareness of their emotional distress, encouraged self-management strategies and provided reassurance from having their experiences validated. In line with the findings of the present study, there were no positive benefits from psychosocial assessment when women perceived the assessment as having little importance to the assessor (Darwin et al., 2013)

\section{Strengths and Limitations}

This study makes a novel contribution to understanding pregnant women's experiences of anxiety. The strength of the study is in its unique exploration amongst women of the use of instruments to identify anxiety in pregnancy. Although one group of 15 women was larger than expected, the disadvantages of facilitating the large FGD were off-set by the benefits. An advantage of working with pre-existing groups is that participants with prior knowledge of other group members can take less time to feel secure when contributing to discussions (Bloor et al., 2001). Interaction within preexisting groups allows the facilitator to access contexts where group ideas and understandings are formed (Kitzinger \& Barbour, 1999).

Another potential limitation was the size of focus group two. However the benefit was that the small group size enabled the women to feel safe in discussing potentially sensitive topics with strangers (Kreuger \& Casey, 2000).

Whilst we acknowledge that not inviting pregnant women or those with a premature or ill baby to the FGDs may have excluded women who experienced high levels of anxiety during pregnancy, we wished to avoid the risk of causing unnecessary further anxiety. It was considered that women in the postnatal period would provide valuable insights into their experiences during their recent 
pregnancies and may have felt more confident discussing these experiences following the birth of their baby. Although it could be argued that asking postnatal women to reflect on events and their feelings during pregnancy may be subject to imprecise recall and interpretation, postnatal women provide valuable insights into their experiences during their recent pregnancies. Simkin (1991) highlighted that women held precise and detailed memories about their birth experiences when interviewed even 15-20 years afterwards. Further studies including FGDs with different women may elicit further issues. This study provides a useful foundation for further research into the use of anxiety instruments in pregnancy.

\section{Conclusion}

The introduction of routine psychosocial assessment including the use of anxiety instruments may offer an opportunity to prompt a discussion around women's emotional health in pregnancy and facilitate the offer of support to women who may benefit. All three instruments explored in this study were acceptable but women preferred the style of questions and concepts in the pregnancy specific instrument. This research found that women would welcome an opportunity to discuss their anxieties with their midwife and with other women with similar concerns. To create the right context for discussion women must feel understood and midwives must have enough the time to discuss any issues revealed. Midwives may benefit from further training to highlight the importance of discussing emotional health in pregnancy, acknowledge the difficulty women may have when expressing their concerns and develop the skills to sensitively address them. Pre-registration midwifery education programmes in England are now required to include a perinatal mental health module, with further provision for post-registration training (Department of Health, 2014). 


\section{References}

Alderdice, F., Lynn, F., \& Lobel, M. (2012). A review and psychometric evaluation of pregnancy-specific stress measures. Journal of Psychosomatic Obstetrics and Gynaecology, 33(2), 62-77.

Armstrong, D. (2004). Impact of prior perinatal loss on subsequent pregnancies. Journal of Obstetric, Gynecologic, \& Neonatal Nursing, 33(6), 765-773.

Armstrong, D., \& Hutti, M. (1998). Pregnancy after perinatal loss: the relationship between anxiety and prenatal attachment. Journal of Obstetric, Gynecologic, and Neonatal Nursing : JOGNN / NAACOG, 27(2), 183-9.

Austin, M. (2003). Psychosocial assessment and management of depression and anxiety in pregnancy. Key aspects of antenatal care for general practice. Australian Family Physician, 32(3), 119-126.

Austin, M., Hadzi-Pavlovic, D., Saint, K., \& Parker, G. (2005). Antenatal screening for the prediction of postnatal depression: validation of a psychosocial Pregnancy Risk Questionnaire. Acta Psychiatrica Scandinavica, 112(4), 310-7.

Austin, M., Priest, S., \& Sullivan, E. (2008). Antenatal psychosocial assessment for reducing perinatal mental health morbidity. The Cochrane Database of Systematic Reviews, (4), CD005124. doi:10.1002/14651858.CD005124.pub2.

Blair, M., Glynn, L., Sandman, C., \& Davis, E. (2011). Prenatal maternal anxiety and early childhood temperament. Stress (Amsterdam, Netherlands), 14(6), 644-51. http://doi.org/10.3109/10253890.2011.594121

Bloor, M., Frankland, J., Thomas, M., \& Robson, K. (2001). Focus Groups in Social Research. London: Sage.

Bonnin, A., Goeden, N., Chen, K., Wilson, M., King, J., Shih, J., Blakely, R., Deneris, E., Levitt, P. (2011). A transient placental source of serotonin for the fetal forebrain. Nature, 472(7343), 347-50.

Buist, A., Condon, J., Brooks, J., Speelman, C., Milgrom, J., Hayes, B., Ellwood, D., Barnett, B., Kowalenko, N., Matthey, S., Austin, M., Bilszta, J. (2006). Acceptability of routine screening for perinatal depression. Journal of Affective Disorders, 93(1-3), 233-7.

Cardwell, M. (2013). Stress: pregnancy considerations. Obstetrical \& Gynecological Survey, 68(2), 119-29. http://doi.org/10.1097/OGX.0b013e31827f2481

Coelho, H., Murray, L., Royal-Lawson, M., \& Cooper, P. (2011). Antenatal anxiety disorder as a predictor of postnatal depression: a longitudinal study. Journal of Affective Disorders, 129(1-3), 348-53.

Côté-Arsenault, D., \& Donato, K. (2011). Emotional cushioning in pregnancy after perinatal loss. Journal of Reproductive and Infant Psychology, 29(1), 81-92.

Cox, J., Holden, J., \& Sagovsky, R. (1987). Detection of postnatal depression. Development of the 10-item Edinburgh Postnatal Depression Scale. The British Journal of Psychiatry: The Journal of Mental Science, 150, 782-6.

Darwin, Z., McGowan, L., \& Edozien, L. (2013). Assessment acting as intervention: findings from a study of perinatal psychosocial assessment. Journal of Reproductive and Infant Psychology, 31(March 2015), 500-511.

Davis, E., \& Sandman, C. (2012). Prenatal psychobiological predictors of anxiety risk in preadolescent children. Psychoneuroendocrinology, 37(8), 1224-33. 
Department of Health. (2014). Delivering high quality, effective, compassionate care: Developing the right people with the right skills and the right values. A mandate from the Government to Health Education England: April 2014 to March 2015. London. Department of Health.

Ding, X.-X., Wu, Y.-L., Xu, S.-J., Zhu, R.-P., Jia, X.-M., Zhang, S.-F., Huang, K., Zhu, P., Hao, J-H., Tao, F.-B. (2014). Maternal anxiety during pregnancy and adverse birth outcomes: a systematic review and meta-analysis of prospective cohort studies. Journal of Affective Disorders, 159, 103-10.

Dunkel Schetter, C., \& Tanner, L. (2012). Anxiety, depression and stress in pregnancy: implications for mothers, children, research, and practice. Current Opinion in Psychiatry, 25(2), 141-8.

Evans, J., Heron, J., Francomb, H., Oke, S., \& Golding, J. (2001). Cohort study of depressed mood during pregnancy and after childbirth. BMJ (Clinical Research Ed.), 323(7307), 257-60.

Evans, K., Spiby, H., \& Morrell, C. (2015). A psychometric systematic review of self-report instruments to identify anxiety in pregnancy. Journal of Advanced Nursing, 71(9), 19862001

Freeman, T. (2006). "Best practice" in focus group research: making sense of different views. Journal of Advanced Nursing, 56(5), 491-7.

Gibbs, A. (1997). Social Research Update 19: Focus Groups. Retrieved May 5, 2015, from http://sru.soc.surrey.ac.uk/SRU19.html

Glover, V. (2014). Maternal depression, anxiety and stress during pregnancy and child outcome; what needs to be done. Best Practice \& Research. Clinical Obstetrics \& Gynaecology, 28(1), 25-35.

Herbert, J., Goodyer, I., Grossman, A., Hastings, M., de Kloet, E., Lightman, S., Lupien, S., Roozendaal, B., Seckl, J. (2006). Do corticosteroids damage the brain? Journal of Neuroendocrinology, 18(6), 393-411.

Heron, J., O'Connor, T. G., Evans, J., Golding, J., \& Glover, V. (2004). The course of anxiety and depression through pregnancy and the postpartum in a community sample. Journal of Affective Disorders, 80(1), 65-73.

Highet, N., Stevenson, A., Purtell, C., \& Coo, S. (2014). Qualitative insights into women's personal experiences of perinatal depression and anxiety. Women and Birth, 27(3), 179184.

Jarrett, P., Green, J., \& Spiby, H. (2009). Women who Present with Mental Health Problems during pregnancy: How Can Midwives be Helped to Manage their Care? Journal of Reproductive and Infant Psychology, 27(3), 310-311.

Jomeen, J., Glover, L., Garg, D., Marshall, C., Jones, C., \& Gardiner, E. (2012). Empowering Health Visitors to predict and detect deleterious mental health during pregnancy and the postnatal period and promote optimal care for childbearing women. University of Hull for the Burdett Trust, Hull.

Keeton, C., Perry-Jenkins, M., \& Sayer, A. (2008). Sense of control predicts depressive and anxious symptoms across the transition to parenthood. Journal of Family Psychology: JFP : Journal of the Division of Family Psychology of the American Psychological Association (Division 43), 22(2), 212-21.

King, N. (2004). Template Analysis. Retrieved May 5, 2015, from 
http://www.hud.ac.uk/hhs/research/template-analysis/

Kitzinger, J., \& Barbour, R. (1999). Introduction: the challenge and promise of focus groups. In R. Barbour \& J. Kitzinger (Eds.), Developing focus group research: politics, theory and practice. London: Sage. pp 1-20.

Knight, M., Tuffnell, D., Kenyon, S., Shakespeare, J., Gray, R., Kurinczuk, J. (Eds.) on behalf of MBRRACE-UK. (2015). Saving Lives, Improving Mothers' Care Surveillance of maternal deaths in the UK 2011-13 and lessons learned to inform maternity care from the UK and Ireland Confidential Enquiries into Maternal Deaths and Morbidity 2009-13. Oxford: National Perinatal Epidemiology Unit, University of Oxford 2015

Krueger, R., \& Casey, M. (2000). Focus Groups: A Practical Guide for Applied Research, 3rd edition. California: Sage.

Larsson, C., Sydsjö, G., \& Josefsson, A. (2004). Health, sociodemographic data, and pregnancy outcome in women with antepartum depressive symptoms. Obstetrics and Gynecology, 104(3), 459-66.

Littleton, H., Breitkopf, C., \& Berenson, A. (2007). Correlates of anxiety symptoms during pregnancy and association with perinatal outcomes: a meta-analysis. American Journal of Obstetrics and Gynecology, 196(5), 424-32.

Mairesse, J., Lesage, J., Breton, C., Bréant, B., Hahn, T., Darnaudéry, M., Dickson, S., Seckl, J., Blondeau, B., Vieau, D., Maccari, S., Viltart, O. (2007). Maternal stress alters endocrine function of the feto-placental unit in rats. American Journal of Physiology. Endocrinology and Metabolism, 292(6), E1526-E1533.

Meades, R., \& Ayers, S. (2011). Anxiety measures validated in perinatal populations: A systematic review. Journal of Affective Disorders, 133, 1-15.

Morgan, D., \& Kreuger, R. (1993). When to use focus groups and why. In D. Morgan (Ed.), Successful Focus Groups: Advancing the State of the Art. London: Sage. pp 3-19.

Morrell, C., Cantrell, A., Evans, K., \& Carrick-Sen, D. (2013). A review of instruments to measure health-related quality of life and well-being among pregnant women. Journal of Reproductive and Infant Psychology, 31(5), 512-530.

Mueller, B., \& Bale, T. (2008). Sex-specific programming of offspring emotionality after stress early in pregnancy. The Journal of Neuroscience: The Official Journal of the Society for Neuroscience, 28(36), 9055-65.

National Institute for Health and Care Excellence. (2014). Antenatal and postnatal mental health: clinical management and service guidance. London. NICE.

Nursing and Midwifery Council. (2015). The Code - Professional standards of practice and behaviour for nurses and midwives. London. NMC.

O'Hara, M. (2009). Postpartum Depression: what we know. Journal of Clinical Psychology, (65), 1258-1269.

Oates, M. (2003). Perinatal Psychiatric Disorders: a leading cause of maternal morbidity and mortality. British Medical Bulletin, (67), 219-229.

Radtke, K., Ruf, M., Gunter, H., Dohrmann, K., Schauer, M., Meyer, A., \& Elbert, T. (2011). Transgenerational impact of intimate partner violence on methylation in the promoter of the glucocorticoid receptor. Translational Psychiatry, 1, e21.

Raymond, N., Pratt, R., Godecker, A., Harrison, P., Kim, H., Kuendig, J., \& O’Brien, J. 
(2014). Addressing perinatal depression in a group of underserved urban women: a focus group study. BMC Pregnancy and Childbirth, 14(1): 336.

Rowe, H., \& Fisher, J. (2015). Women's Studies International Forum Do contemporary social and health discourses arouse peripartum anxiety? A qualitative investigation of women's accounts. Women's Studies International Forum, 51, 56-65.

Rubertsson, C., Hellstrom, J., Cross, M., \& Sydsjo, G. (2014). Anxiety in early pregnancy: Prevalence and contributing factors. Archives of Women's Mental Health, 17(3), 221228.

Simkin, P. (1991). Just Another Day in a Woman's Life? Women's Long-Term Perceptions of Their First Birth Experience. Part I. Birth, 18(4), 203-210.

Staneva, A., Bogossian, F., \& Wittkowski, A. (2015). The experience of psychological distress, depression, and anxiety during pregnancy: A meta-synthesis of qualitative research. Midwifery, 31(6), 563-573.

Stein, A., Pearson, R., Goodman, S., Rapa, E., Rahman, A., Mccallum, M., Howard, L., Pariante, C. (2014). Eff ects of perinatal mental disorders on the fetus and child. The Lancet, 384(9956), 1800-1819.

Van den Bergh, B. (1990). The influence of maternal emotion during pregnancy on fetal and neonatal behavior. Journal of Prenatal \& Perinatal Psychology \& Health, 5(2), 119130.

Vythilingum, B. (2009). Anxiety disorders in pregnancy and the postnatal period. Continuing Medical Education, 27(10), 8-10.

Whitfield, G. (2010). Group cognitive-behavioural therapy for anxiety and depression. Advances in Psychiatric Treatment, 16(3), 219-227.

Yalom, I. (1995). The Theory and Practice of Group Psychotherapy (4th edn). New York: Basic Books.

Zigmond, A., \& Snaith, R. (1983). The hospital anxiety and depression scale. Acta Psychiatrica Scandinavica, 67(6), 361-70. 